\title{
Pectinase: Substrate, Production and their Biotechnological Applications
}

\author{
Oliyad Jeilu Oumer
}

\author{
Ambo University, Department of Biology, Ambo
}

\begin{abstract}
Pectinolytic enzymes can be applied in various industrial sectors wherever the degradation of pectin is required for a particular process. Several microorganisms have been used to produce different types of pectinolytic enzymes. Microbial pectinases account for $25 \%$ of the global food and industrial enzyme sales and their market is increasing day by day. Owing to the enormous potential of Pectinase in various sectors of industries whenever degradation of pectin is needed, this review broadly focus on types of pectin substances, pectinase, their production as well as their biotechnologically potential applications.
\end{abstract}

Keywords - Pectinase, Biotechnological Applications.

\section{INTRODUCTION}

The plant cell wall is a complex macromolecular structure that surrounds and protects the cell, and is a distinguishing characteristic of plants essential to their survival. As a consequence of limited mobility, plants are plastic in their ability to withstand a variety of harsh environmental conditions and to survive attack by pathogens and herbivores. The structure formed by the polysaccharides, proteins, aromatic, and aliphatic compounds of the cell wall enables plants to flourish in diverse environmental niches. Cell wall structure is continually modified to accommodate the developmental stage and the environmental condition. The plant cell lays down the middle lamella and the primary wall during initial growth and expansion of the cell. In many cells, the wall is thickened and further strengthened by the addition of a secondary wall. The primary wall is thought to contribute to wall structural integrity, cell adhesion, and signal transduction(Caffall and Mohnen 2009).

The structural constituents of a young plant cell wall are cellulose, hemicellulose and pectic substances. The cellulose micro fibrils provide strength to the cell wall, while hemicelluloses and pectic substances act as the cementing substance for the cellulose network. Pectins or pecticsubstances contribute to complex physiological processes like cell growth and cell differentiation and so determine the integrity and rigidity of plant tissue.
Polysaccharides from cell walls of ripe pears were reported to contain $11.5 \%$ pectic substances, $16.1 \%$ lignin, $21.4 \%$ glucosan, $3.5 \%$ galactan, $1.1 \%$ mannan, $21 \%$ xylan and $10 \%$ arabinan(Horikoshi 1999).

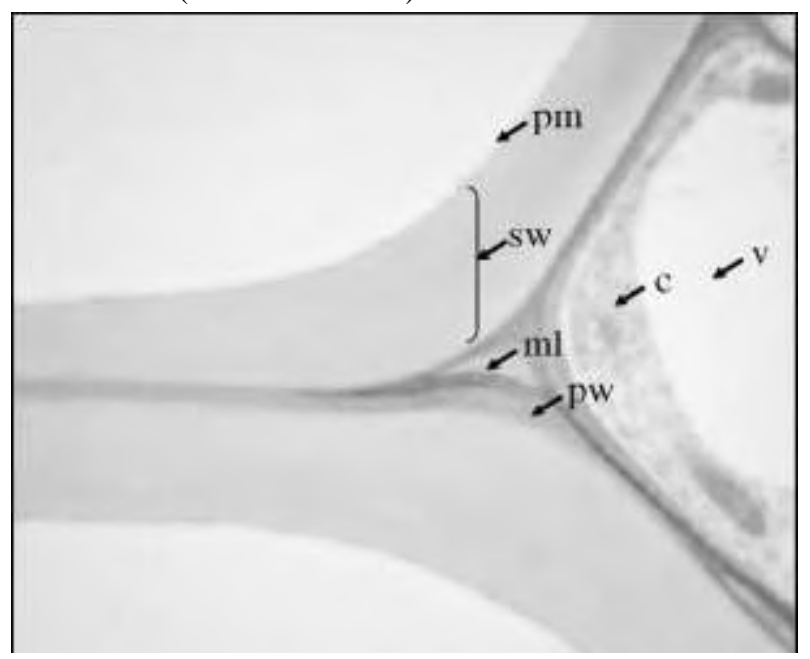

Fig.1: The cell wall of Arabidopsis thaliana. middle lamella $(\mathrm{ml})$, primary wall $(\mathrm{pw})$, secondary wall (sw) of the metaxylem. plasma membrane (pm), cytosol (c) and vacuole (v)(Caffall and Mohnen, 2009)

Pectic substances are polysaccharides of high molecular weight, with a negative charge, appearing mostly in the middle lamella and the primary cell wall of higher plan(Osborne, 2004). They are formed by a central chain containing a variable amount although in high proportion of galacturonic acid residues linked through $\alpha-(1-4)$ glycosidic bonds partially esterified with methyl groups. This molecule is known as pectin, while the demethylated molecule is known as polygalacturonic acid or pectic acid. Pectin was discovered in 1790 by Vauquelin and later in 1825 crudely characterized by Braconnot (Caffall and Mohnen, 2009).

Compared with young, actively growing tissues, lignified tissues have a low content of pectic substances. The content of the pectic substances is very low in higher plants usually less than $1 \%$. They are mainly found in fruits and vegetables, constitute a large part of some algal biomass (up 
to $30 \%$ ) and occur in low concentration in forestry or agricultural residues (Horikoshi 1999).

\section{CLASSIFICATION OF PECTIC SUBSTANCES}

Based on the type of modifications of the backbone chain, The American Chemical Society classified pectic substances into four main types as protopectin, pectic acid, pectinic acid and pectin(Alkorta et al. 1998; Abalos et al. 2002; Kashyap et al. 2001).

\section{Protopectin}

This is a parent pectic substance and upon restricted hydrolysis yields pectin or pectinic acid. Protopectin is occasionally a term used to describe the water-insoluble pectic substances found in plant tissues and from which solublepectic substances are produced (Neill 2001).

\section{Pectic Acids}

These are the galacturonans that contain negligible amounts of methoxyl groups. Normal or acid salts of pectic acid are called pectates.

\section{Pectinic Acids}

These are the galacturonans with various amounts of methoxyl groups. Pectinates are normal or acid salts of pectinic acids. Pectinic acid alone has the unique property of forming a gel with sugar. The salts of pectinic acids are either normal or acid pectinates. Under suitable conditions, pectinic acids are capable of forming gels with sugars and acids or if suitably low in methoxyl content with certain metallic ions (Neill 2001).

\section{Pectin (polymethylgalacturonate)}

It is polymeric material in which, at least, $75 \%$ of the carboxyl groups of the galacturonate units are esterified with methanol. It confers rigidity on cell wall when it is bound to cellulose in the cell wall. Pectins are the soluble polymeric materials containing pectinic acids as the major component. They can form insoluble protopectins with other structural polysaccharides and proteins located in the cell wall (Kashyap et al. 2001). Pectin substance consists of pectin and pectic acid. Demethylated pectin is known as pectic acid or polygalacturonic acid.

\section{Structure of Pectic substances}

Pectic substances are complex colloidal acid polysaccharides, with a backbone of galacturonicacid residues linked by $\alpha(1 \rightarrow 4)$ linkage. The side chains of the pectin molecule consist of L-rhamnose, arabinose, galactose and xylose. The carboxyl groups of galacturonic acid are partially esterified by methyl groups and partially or completely neutralized by Sodium, Potassium or Ammonium ions(Limberg et al. 2000; Kuhad, Kapoor, and Rustagi 2004).
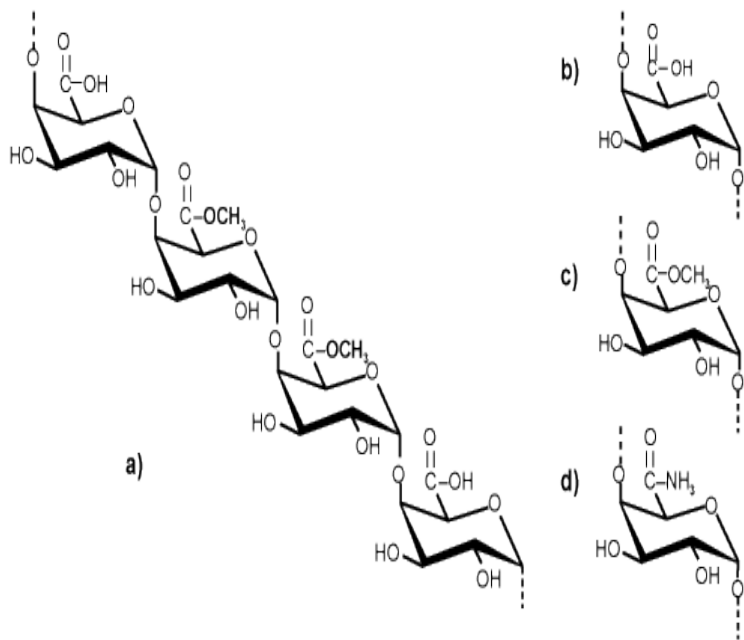

Fig.2: (a) A repeating segment of pectin molecule and functional groups: (b) carboxyl; (c) ester; (d) amide in pectin chain.

It is one of the most complex bio-macromolecules in nature and it can be composed of as many as 17 different monosaccharides, with at least seven different polysaccharides (Jayani, et al., 2005).The structural classes of the pectic polysaccharides include homogalacturonan (HG), xylogalacturonan (XGA), apiogalacturonan (AGA), rhamnogalacturonan II (RG-II), and rhamnogalacturonan I (RG-I)(Neill 2001)(Neill, 2001). 


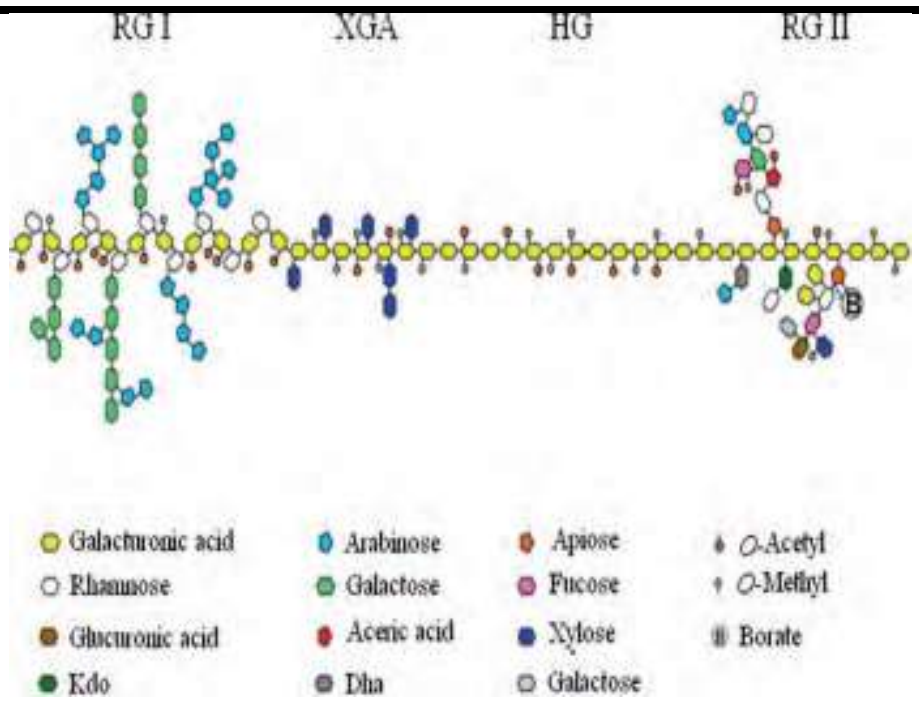

Fig.3: Schematic structure of pectin. The major polysaccharides are HG, XGA, RG II and RG I (Jacob et al. 2008)

\section{Applications of Pectins}

Pectins show widespread commercial use, especially in the textile industry and in the food industry as thickener, texturizer, emulsifier, stabilizer, filler in confections, dairy products, and bakery products etc. In the food sector, it is primarily used as a gelling agent, replacing sugars and/or fats in low-calorie food and as nutritional fiber (Sakai et al. 1993). It is also studied for its potential in drug delivery, in the pharmaceutical industry and is interesting as a dietary supplementation to humans due to its possible cholesterollowering effect. These polysaccharides are which can also reduce the toxicity of these and make their activity longer lasting without altering their therapeutic effects (Morris et al. 2010). Pectin also has a potential in making biodegradable films. Despite these applications, pectins are similar to cellulose and hemicelluloses, in converting common waste materials to soluble sugars, ethanol and biogas (Hutnan, Drtil, and Mrafkova 2000).

\section{Pectinase}

Pectinases are a heterogeneous group of related enzymes that hydrolyze the pectin substances, present mostly in plants. Pectic enzymes are widely distributed in nature and are produced by bacteria, yeast, fungi and plants (Babu and Bayer 2014). In plants, pectic enzymes are very important since they play a role in elongation and cellular growth as well as in fruit ripening (Jansirani et al. 2014). Pectolytic activity of microorganisms plays a significant role, firstly, in the pathogenesis of plants since these enzymes are the first to attack the tissue (Ovodov 2009). In addition, they are also involved in the process of symbiosis and the decay of vegetable residues(Hoondal et al. 2002). Thus by breaking down pectin polymer for nutritional purposes, microbial pectolytic enzymes play an important role in nature (Yadav et al. 2009). These enzymes are inducible, produced only when needed and they contribute to the natural carbon cycle (Hoondal et al. 2002).

\section{Classification of Pectinases}

According to the cleavage site, pectinases are divided into three groups: (1) hydrolases consisting of polygalacturonase, PG (EC 3.2.1.15); (2) lyase/transeliminases comprising pectinlyase, PNL (EC 4.2.2.10), and pectate lyase, PL (EC 4.2.2.2); (3) pectin esterase, PE (EC 3.1.1.11) (Yadav et al. 2009; Osborne 2004).

\section{Pectinesterase (PE)}

Pectin methyl esterase or pectinesterase (EC 3.1.1.11) catalyzes deesterification of the methoxyl group of pectin forming pectic acid and methanol. The enzyme acts preferentially on a methyl ester group of galacturonate unit next to a non-esterified galacturonate unit. It acts before polygalacturonases and pectate lyases which need nonesterified substrates (Kashyap et al. 2001).

\section{Polygalacturonase (EC 3.2.1.15)}

Polygalacturonases (PGases) are the pectinolytic enzymes that catalyse the hydrolytic cleavage of the polygalacturonic acid chain with the introduction of water across the oxygen bridge (Kashyap et al. 2001).

\section{Pectatelyase (EC 4.2.2.2)}


Pectatelyase (PGL) cleaves glycosidic linkages preferentially on polygalacturonic acid forming unsaturated product through transelimination reaction. PGL has an absolute requirement of $\mathrm{Ca}^{2+}$ ions. Hence it is strongly inhibited by chelating agents as EDTA(Jayani, Saxena, and Gupta 2005a).

\section{Pectin lyase (EC 4.2.2.10)}

Pectin lyase catalyzes the random cleavage of pectin, preferentially high esterified pectin, producing unsaturated methyloligogalacturonates through transelimination of glycosidic linkages. PLs do not have an absolute requirement of $\mathrm{Ca}^{2+}$ but they are stimulated by this and other cations (Jayani, Saxena, and Gupta 2005b).
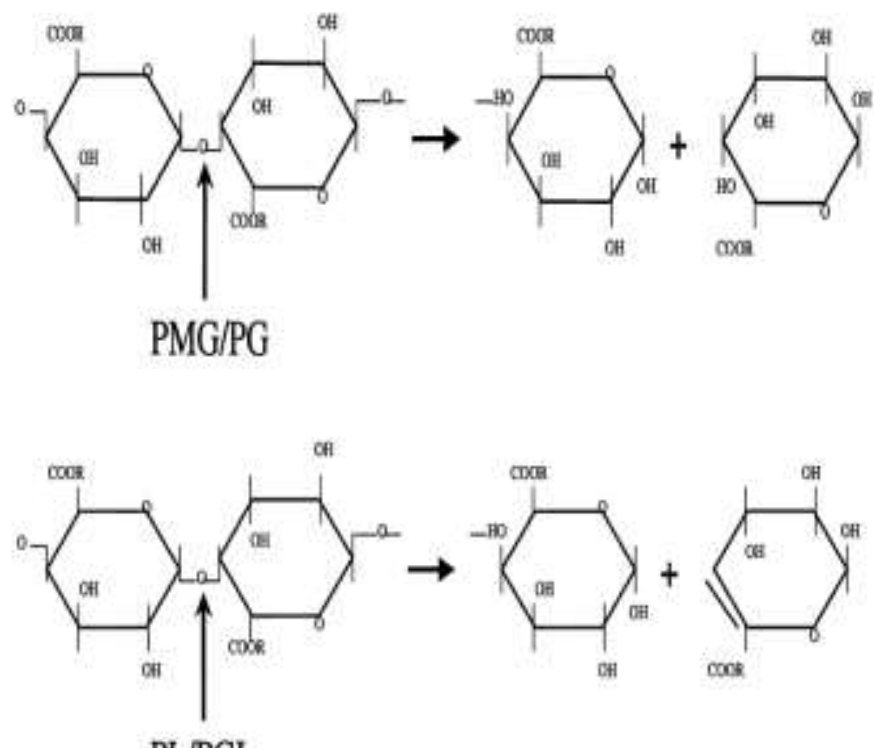

PL/PGL
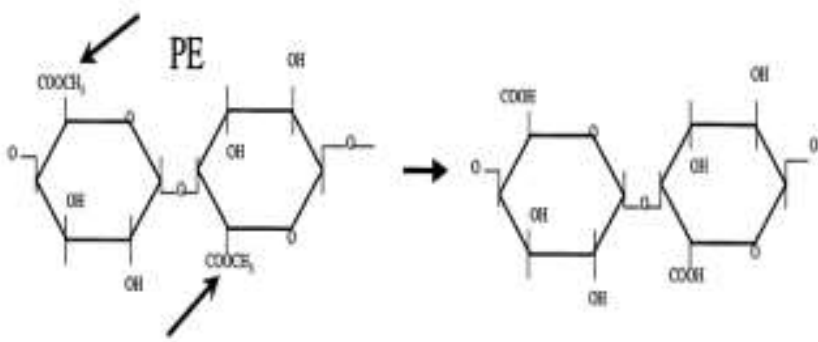

$\mathrm{PE}$

Fig.4: Mode of action of Pectinases; PMG is polymethylgalacturonase, $P G$ is polygalacturonase, $P L$ is pectin lyase, $P E$ is pectinesterase. $R$ group is $H$ in case of $P G, C H 3$ in case of PGL. $R$ group is $C H 3$ in case of $P L, H$ in case of PGL(Mohnen 2008).

\section{Production of Microbial Pectinase}

Microorganisms are currently the primary source of industrial enzymes: $50 \%$ originate from fungi and yeast; $35 \%$ from bacteria, while the remaining $15 \%$ are either of plant origin. The microbial world has shown to be very heterogeneous in its ability to synthesize different types of pectolytic enzymes with different mechanisms of action and biochemical properties (Gummadi and Panda 2003). There were two fermentation techniques we can use for pectinases production, as many other enzymes. These techniques are Solid State Fermentation (SSF) and submerged fermentation $(\mathrm{SmF})$.

Solid state fermentation is defined as the cultivation of microorganisms on moist solid supports, either on inert carriers or on insoluble substrates that can be used as carbon and energy source. This process occurs in the absence or near absence of free water in the space between substrate particles. In this system, water is present in the solid substrate whose capacity for liquid retention varies with the type of material (Pandey, Soccol, Nigam, Soccol, et al. 2000). In contrast, in submerged fermentation (SmF) the nutrients and microorganisms are both submerged in water. Approximately $90 \%$ of all industrial enzymes are produced in $\mathrm{SmF}$, frequently using specifically optimized, genetically manipulated microorganisms. In this respect $\mathrm{SmF}$ processing offers an insurmountable advantage over SSF. SSF has several advantages over SmF system such as higher concentration of products, less effluent generation, requirement for simple equipmentsetc(Pandey et al. 1999). The price of commercially available enzymes which are produced mostly by submerged fermentation is usually too high for agro-biotechnological applications. An alternative technique of enzyme production is solid state cultures(Kawano et al. 1999).

Microbial production of pectinases has been studied during recent years (Kashyap et al. 2001). Pectinase production has been reported from bacteria including actinomycetes(Beg et al. 2000), yeast (Reid and Ricard 2000) and fungi. However, almost all the commercial preparations of pectinases are produced from fungal sources (Singh, Ramakrishna, and Appu Rao 1999). Aspergillus niger is the most commonly used fungal species for industrial production of pectinolytic enzymes (Gummadi and Panda 2003; Murad and Azzaz 2011; Jayani, Saxena, and Gupta 2005b).

Most extracellularly induced enzymes are known to be synthesized in higher quantities when inducers are present in the cultivation medium (Alkorta et al. 1998). The production of pectolytic enzymes using different sources 
and the effect of physical parameters such as temperature, aeration rate and type of fermentation were investigated and reported in literature(Naidu and Panda 1998). Pectolytic enzymes have been reported to be induced by several substances. In many cases pectin itself has been used. Many investigators had used complex media such as beet sugar, wheat bran, ground nut meal, citrus fruit peels etc(Hoondal et al. 2002).

Higher cost of the production is perhaps the major constraint in commercialization of new sources of enzymes. Though, using high yielding strains, optimal fermentation conditions and cheap raw materials as a carbon source can reduce the cost of enzyme production for subsequent applications in industrial processes (Murad and Azzaz 2011).

There are many studies that have been conducted related to the characterization of different microbial pectic enzymes concerning their mechanisms of action and biochemical properties. The optimal $\mathrm{pHs}$ that these enzymes may act range between 3.5-11, while the optimal temperatures vary between $40-75{ }^{\circ} \mathrm{C}$ (Gummadi and Panda 2003; Kashyap et al. 2001).

\section{Biotechnological Applications of Microbial Pectinases}

Application of enzymes in biotechnological process has expanded considerably in recent years. In food and related industry, major importance was being attached to the use of enzymes in upgrading quality, increasing yields of extractive processes, product stabilization, and improvement of flavor and by product utilization (Patil and Dayanand 2006). Pectinases or pectinolytic enzymes are today one of the upcoming enzymes of the commercial sector. It has been reported that microbial pectinases account for $25 \%$ of the global food enzymes sales ((Jayani, Saxena, and Gupta 2005b). On the bases of their applications, pectinases are mainly of two types: acidic pectinases and alkaline pectinases(Jayani, et al., 2005; Murad and Azzaz 2011).

\section{Acidic Pectinases}

Acidic pectic enzymes used in the fruit juice industries and wine making often come from fungal sources, especially from Aspergillusniger(Kashyap et al. 2001). Potential applications of Acidic pectinase are briefly described below.

\section{Fruit juice clarification/extraction}

Fruit juice clarification/extraction is one among the important applications of acidic pectinases Fruit juices contain colloids that may lead to fouling problem during filtration process and these colloids are basically polysaccharides such as pectin and starch (Rai et al. 2004). Pre-treatment of juices with pectinases is performed to lower the amount of pectin present and to decrease the viscosity of the juice, which in turn accelerates the subsequent filtration process. Also, it helps to increase the clarity of the juice.

\section{Tissue maceration}

Tissue maceration is another important application of acidic pectinases in which organized tissue is transformed into a suspension of intact cells and it is significant in the food industry as well as in the field of biotechnology. The process can be applied for the liquefaction and saccharification of biomass, isolation of protoplasts.

\section{Wine processing}

Wine processing industry also recognizes the importance of acidic pectinases (Roldán et al. 2010), where the enzyme can be applied at different stages. The addition of pectinases during crushing of the fruits increases the juice yield and also accelerates the release of anthocyanins into the juice. Pectinase treatment at the pre-fermentation or fermentation stage, settles out suspended particles. After fermentation, enzyme is added to the wine to increase its clarity and filtration rate (Kashyap et al. 2001).

\section{Alkaline pectinases}

Alkaline pectinases are mainly used in the degumming and retting of fibeber crops and pretreatment of pectic wastewater from fruit juice industries. These enzymes come mostly from bacterial sources (Kashyap et al. 2001). In the industrial sector, alkaline pectinases, mainly from Bacillus spp. are applied for the following purposes.

\section{Paper and pulp industry}

During papermaking, pectinase can depolymerisepectins and subsequently lower the cationic demand of pectin solutions and the filtrate from peroxide bleaching (Reid and Ricard 2000).

\section{Retting and degumming of plant bast fibers}

Bast fibers are the soft fibers formed in groups outside the xylem, phloem or pericycle, e.g. Ramie and sun hemp. The fibers contain gum, which must be removed before its use for textile making. The chemical degumming treatment is polluting, toxic and non-biodegradable. Biotechnological degumming using pectinases in combination with xylanases 
presents an eco-friendly and economic alternative to the above problem (Kapoor et al. 2001). Pectinases have been used in retting of flax to separate the fibers and eliminate pectins(Hoondal et al. 2002).

\section{Textile processing and bio-scouring of cotton fibers}

Pectinases have been used in conjunction with amylases, lipases, cellulases and hemi-cellulases to remove sizing agents from cotton in a safe and eco-friendly manner, replacing toxic caustic soda used for the purpose earlier. Bio-scouring is a novel process for removal of noncellulosic impurities from the fiber with specific enzymes. Pectinases have been used for this purpose without any negative side effect on cellulose (Hoondal et al. 2002).

\section{Pectic waste water treatment}

The wastewater from the citrus-processing industry contains pectinaceous materials that are barely decomposed by microbes during the activated-sludge treatment have tried to develop a new wastewater treatment process by using an alkalophillic microorganism. Pretreatment of these wastewaters with pectinolytic enzymes facilitates removal of pectinaceous material and renders it suitable for decomposition by activated sludge treatment (Beg et al. 2000).

\section{Animal feed}

Pectinases are used in the enzyme cocktail, used for the production of animal feeds. This reduces the feed viscosity, which increases absorption of nutrients, liberates nutrients, either by hydrolysis of non-biodegradable fibers or by liberating nutrients blocked by these fibers, and reduces the amount of faeces(Jayani, Saxena, and Gupta 2005b).

\section{Oil extraction}

Citrus oils such as lemon oil can be extracted with pectinases. They destroy the emulsifying properties of pectin, which interferes with the collection of oils from citrus peel extracts(Mohnen 2008).

\section{Purification of plant viruses}

Pectinases have also been reported to work on purification of viruses. But they are yet to be commercialized. When virus particle is restricted to phloem, to release the virus from the tissues, alkaline pectinases and cellulases are used. This gives very pure preparations of the virus (Reid and Ricard 2000).

\section{Coffee and tea fermentation}

Fermentation of coffee using pectinolytic microorganisms is done to remove the mucilage coat from the coffee beans and to enhance the tea fermentation and foam forming property of tea. Fungal pectinases are also used in the manufacture of tea. Enzyme treatment accelerates tea fermentation, although the enzyme dose must be adjusted carefully to avoid damage to the tea leaf. Large-scale treatment of coffee with commercial pectinases is costly and uneconomical, inoculated waste mucilage is used as a source of microbial pectin enzymes. The fermentation liquid is washed, filtered and then sprayed on to the beans (Pandey, Soccol, Nigam, Brand, et al. 2000).

\section{CONCLUSION}

Biotechnological answers for environmental sustainability are modern solutions that help in the growth of the nation and are a boon for the welfare of human beings for the present and forthcoming generations. Application of biotechnology to industrial operations for enzyme production is no longer an academic or potentially useful alternative proposition for the future. Owing to the enormous potential of Pectinase in various sectors of industries whenever degradation of pectin is needed, it is important to undertake research in screening of microorganisms for pectinase and investigate optimal conditions for production of microbial pectinase.

\section{REFERENCES}

[1] Abalos, a., F. Maximo, M. a. Manresa, and J. Bastida. 2002. "Utilization of Response Surface Methodology to Optimize the Culture Media for the Production of Rhamnolipids by Pseudomonas Aeruginosa AT10." Journal of Chemical Technology and Biotechnology 77 (October 2001): 777-84. doi:10.1002/jctb.637.

[2] Alkorta, Itziar, Carlos Garbisu, María J. Llama, and Juan L. Serra. 1998. "Industrial Applications of Pectic Enzymes: A Review." Process Biochemistry. doi:10.1016/S0032-9592(97)00046-0.

[3] Babu, Yashodar, and Martin Bayer. 2014. "Plant Polygalacturonases Involved in Cell Elongation and Separation-The Same but Different?" Plants 3 (4): 613-23. doi:10.3390/plants3040613.

[4] Beg, Q K, B Bhushan, M Kapoor, and G S Hoondal. 2000. "Production and Characterization of Thermostable Xylanase and Pectinase from Streptomyces Sp. QG-11-3.” Journal of Industrial Microbiology and Biotechnology 24: 396-402. doi:10.1038/sj.jim.7000010. 
[5] Caffall, Kerry Hosmer, and Debra Mohnen. 2009. "The Structure, Function, and Biosynthesis of Plant Cell Wall Pectic Polysaccharides." Carbohydrate Research 344 (14). Elsevier Ltd: 1879-1900. doi:10.1016/j.carres.2009.05.021.

[6] Gummadi, Sathyanarayana N., and T. Panda. 2003. "Purification and Biochemical Properties of Microbial Pectinases-a Review." Process Biochemistry 38: 987-96. doi:10.1016/S0032-9592(02)00203-0.

[7] Hoondal, G., R. Tiwari, R. Tewari, N. Dahiya, and Q. Beg. 2002. "Microbial Alkaline Pectinases and Their Industrial Applications: A Review." Applied Microbiology and Biotechnology. doi:10.1007/s00253-002-1061-1.

[8] Horikoshi, Koki. 1999. "Alkaliphiles: Some Applications of Their Products for Biotechnology" 63 (4): 735-50.

[9] Hutnan, M., M. Drtil, and L. Mrafkova. 2000. "Anaerobic Biodegradation of Sugar Beet Pulp." Biodegradation $11 \quad$ (4): 203-11. doi:10.1023/A:1011139621329.

[10] Jacob, Nicemol, K. N. Niladevi, G. S. Anisha, and P. Prema. 2008. "Hydrolysis of Pectin: An Enzymatic Approach and Its Application in Banana Fiber Processing." Microbiological Research 163 (5): 53844. doi:10.1016/j.micres.2006.07.016.

[11] Jansirani, D., R. Saradha, J. Selvapriyadharshini, N. Salomideborani, N.R. Halimuthul, N.J. Jerin, and Ranjana. 2014. "Production of Pectinase by Bacillus Sp., Isolated from Soil." Journal of Chemical and Pharmaceutical SciencesISSN JCHPS Special Issue 4: 974-2115. www.jchps.com.

[12] Jayani, Ranveer Singh, Shivalika Saxena, and Reena Gupta. 2005a. "Microbial Pectinolytic Enzymes: A Review" 40: 2931-44. doi:10.1016/j.procbio.2005.03.026.

[13] _ 2005b. "Microbial Pectinolytic Enzymes: A Review." Process Biochemistry. doi:10.1016/j.procbio.2005.03.026.

[14] Kapoor, Mukesh, Qasim Khalil Beg, Bharat Bhushan, Kamaljit Singh, K. S. Dadhich, and G. S. Hoondal. 2001. "Application of an Alkaline and Thermostable Polygalacturonase from Bacillus Sp. MG-Cp-2 in Degumming of Ramie (Boehmeria Nivea) and Sunn Hemp (Crotalaria Juncea) Bast Fibres." Process Biochemistry 36 (8-9): 803-7. doi:10.1016/S00329592(00)00282-X.
[15] Kashyap, D R, P K Vohra, S Chopra, and R Tewari. 2001. "Applications of Pectinases in the Commercial Sector: A Review" 77: 215-27.

[16] Kawano, C Y, M a Chellegatti, S Said, and M J Fonseca. 1999. "Comparative Study of Intracellular and Extracellular Pectinases Produced by Penicillium Frequentans." Biotechnology and Applied Biochemistry 29 ( Pt 2) (August 2016): 133-40. doi:10.1111/j.1470-8744.1999.tb00542.x.

[17] Kuhad, Ramesh Chander, Mukesh Kapoor, and Renuka Rustagi. 2004. "Enhanced Production of an Alkaline Pectinase from Streptomyces Sp. RCK-SC by Whole-Cell Immobilization and Solid-State Cultivation." World Journal of Microbiology and Biotechnology $20 \quad$ (3): 257-63. doi:10.1023/B:WIBI.0000023833.15866.45.

[18]Limberg, Gerrit, Roman Körner, Hans Christian Buchholt, Tove M I E Christensen, Peter Roepstorff, and Jørn Dalgaard Mikkelsen. 2000. "Quantification of the Amount of Galacturonic Acid Residues in Blocksequences in Pectin Homogalacturonan by Enzymatic Fingerprinting with Exo- and EndoPolygalacturonase II from Aspergillus Niger." Carbohydrate Research 327 (3): 321-32. doi:10.1016/S0008-6215(00)00068-9.

[19] Mohnen, Debra. 2008. "Pectin Structure and Biosynthesis." Current Opinion in Plant Biology 11: 266-77. doi:10.1016/j.pbi.2008.03.006.

[20] Morris, Gordon, Samil Kök, Stephen Harding, and Gary Adams. 2010. "Polysaccharide Drug Delivery Systems Based on Pectin and Chitosan." Biotechnology \& Genetic Engineering Reviews 27 (15): 257-84. doi:10.1080/02648725.2010.10648153.

[21] Murad, H.a., and H.H. Azzaz. 2011. "Microbial Pectinases and Ruminant Nutrition." Research Journal of Microbiology. doi:10.3923/jm.2011.246.269.

[22] Naidu, G. S N, and T. Panda. 1998. "Production of Pectolytic Enzymes - A Review." Bioprocess Engineering. doi:10.1007/s004490050532.

[23] Neill, Malcolm A O. 2001. "Pectic Substances," 1-11.

[24] Osborne, D. J. 2004. "Advances in Pectin and Pectinase Research. * Voragen F, Schols H and Visser R. Eds. 2003. The Netherlands: Kluwer Academic Publishers. 145 (Hardback). 491 Pp." Annals of Botany 94 (3): 479-80. doi:10.1093/aob/mch146.

[25] Ovodov, Yu. S. 2009. "Current Views on Pectin Substances." Russian Journal of Bioorganic Chemistry 35 (3): 269-84. doi:10.1134/S1068162009030017. 
[26] Pandey, Ashok, P. Selvakumar, Carlos R. Soccol, and Poonam Nigam. 1999. "Solid State Fermentation for the Production of Industrial Enzymes." Current Science.

[27] Pandey, Ashok, Carlos R. Soccol, Poonam Nigam, Debora Brand, Radjiskumar Mohan, and Sevastianos Roussos. 2000. "Biotechnological Potential of Coffee Pulp and Coffee Husk for Bioprocesses." Biochemical Engineering Journal 6 (2): 153-62. doi:10.1016/S1369-703X(00)00084-X.

[28] Pandey, Ashok, Carlos R. Soccol, Poonam Nigam, Vanete T. Soccol, Luciana P S Vandenberghe, and Radjiskumar Mohan. 2000. "Biotechnological Potential of Agro-Industrial Residues. II: Cassava Bagasse." Bioresource Technology. doi:10.1016/S0960-8524(99)00143-1.

[29] Patil, Sarvamangala R., and A. Dayanand. 2006. "Production of Pectinase from Deseeded Sunflower Head by Aspergillus Niger in Submerged and SolidState Conditions." Bioresource Technology 97 (16): 2054-58. doi:10.1016/j.biortech.2005.09.015.

[30] Rai, P., G. C. Majumdar, S. DasGupta, and S. De. 2004. "Optimizing Pectinase Usage in Pretreatment of Mosambi Juice for Clarification by Response Surface Methodology." Journal of Food Engineering 64 (3): 397-403. doi:10.1016/j.jfoodeng.2003.11.008.

[31] Reid, Ian, and Michelle Ricard. 2000. "Pectinase in Papermaking: Solving Retention Problems in Mechanical Pulps Bleached with Hydrogen Peroxide." Enzyme and Microbial Technology 26 (2-4): 115-23. doi:10.1016/S0141-0229(99)00131-3.

[32] Roldán, Ana, Victor Palacios, Ildefonso Caro, and Luis Pérez. 2010. "Evolution of Resveratrol and Piceid Contents during the Industrial Winemaking Process of Sherry Wine." Journal of Agricultural and Food Chemistry 58 (7): 4268-73. doi:10.1021/jf9038666.

[33] Sakai, Takuo, Tatsuji Sakamoto, Johan Hallaert, and Erick J. Vandamme. 1993. "PPectin, Pectinase, and Protopectinase: Production, [ Properties, and Applications." Advances in Applied Microbiology 39: 213-94. doi:10.1016/S0065-2164(08)70597-5.

[34] Singh, Sridevi Annapurna, M. Ramakrishna, and A. G. Appu Rao. 1999. "Optimisation of Downstream Processing Parameters for the Recovery of Pectinase from the Fermented Bran of Aspergillus Carbonarius." Process Biochemistry 35 (3-4): 411-17. doi:10.1016/S0032-9592(99)00089-8.

[35] Yadav, P K, V K Singh, S Yadav, K D S Yadav, and D Yadav. 2009. "In Silico Analysis of Pectin Lyase and Pectinase Sequences." Biochemistry. Biokhimiia 74 (9): 1049-55. doi:10.1134/S0006297909090144. 